\title{
MOLECULAR DIAGNOSIS OF CRYPTOSPORIDIUM SPP. VERSUS MICROSCOPY IN DIARRHEIC PATIENTS IN CAIRO
}

\author{
By \\ OLFAT M. ELMATRAWY ${ }^{1}$, MARWA A. HASSAN ${ }^{1}$, SALWA M. MORSY ${ }^{1 *}$, \\ JOSE M. RUBIO ${ }^{2}$ and AYMAN A. EL-BADRY ${ }^{3}$
}

Department of Medical Parasitology ${ }^{1}$, Kasr Al-Ainy Faculty of Medicine, Cairo University, Egypt; Malaria \& Emerging Parasitic Diseases Laboratory ${ }^{2}$. National Microbiology Centre, Institute de Salud Carlos III Madrid, Spain, and Department of Microbiology-Medical Parasitology Section ${ }^{3}$, Faculty of Medicine, University of

Dammam, Dammam, Saudi Arabia

( ${ }^{*}$ Correspondence: Email: smmorsy@kasralainy.edu.eg; Fax: 01125337304)

\begin{abstract}
Cryptosporidium spp. is considered one of the most common diarrhea-causing protozoa. This cross-sectional study was designed for molecular detection of Cryptosporidium spp., comparing results with microscopy using Acid Fast (AF) staining, and to determine predominance of cryptosporidiosis according to patients' age and gender.

Methodology: Stool samples were collected from 150 diarrheic patients attending outpatient clinics of Kasr Al-Ainy School of Medicine, Cairo University. Samples were examined microscopically by direct wet mount before and after sample concentration, and then subjected to copro-PCR assays.

The results showed that out of 150 samples subjected to nPCR, only $9(6 \%)$ samples were positive for Cryptosporidium spp. and of those, $2(1.3 \%)$ were positive by microscopy using AF stain. Microscopy showed high specificity but lower sensitivity (22\%) compared to nPCR. Six of the 9 molecularly positive cases $(66.7 \%)$ were children under 9 years and predominantly females with statistical significance.
\end{abstract}

Key words: Patients, Cryptosporidium spp., AF stain, nested PCR.

\section{Introduction}

In the developing countries, diarrhea is considered the second most common cause of morbidity \& mortality in children (WHO, 2012; WGO, 2013). Cryptosporidiosis is a frequent cause of diarrheal disease in man, particularly children and immunocompromised patients lead to devastating outcomes (Fayer et al, 2000). In Egypt, Cryptosporidium reports of prevalent \& virulent diarrheal agent, mainly in childhood varied between 5.0-31.1\% (Abdel-Messih et al, 2005; ElShazly et al, 2007; Youssef et al, 2008; Mousa et al, 2010; Abdel Kader et al, 2012; Fathy et al, 2014; El-Badry et al, 2015; Abdel razek et al, 2016; Ghallab et al, 2016).

Microscopic diagnosis alone was neither sensitive nor specific as multiple sampling, concentration and staining techniques are needed to improve its performance (Hamzah et al, 2010). More specific and sensitive alternative methods, including PCR and anti- gen detection tests, were also used for detection of cryptosporidiosis. PCR assays are increasingly available, yielding better sensitivity and specificity in comparison to the microscopy and antigen detection assays (Ghosh et al, 2000; Stark et al, 2008). Realtime PCR identified Cryptosporidium spp. (Haque et al, 2007) and determined its burden as enabling parasite quantification (Calderaro et al, 2010; Hadfield et al, 2011).

This cross-sectional study was designed for molecular detection of Cryptosporidium spp., comparing results with microscopy using AF staining, and to determine predominance of cryptosporidiosis according to patients' age and sex.

\section{Materials and Methods}

Study design and population: A cross sectional study was performed for 150 diarrheic patients attending Outpatient Clinics of Kasr Al-Ainy Hospitals, Cairo University from January 2015 to October 2015. Patients of 
both sexes, aged from 1 to 60 years, old suffering from diarrhea, with or without other GIT symptoms as abdominal pain, vomiting, flatulence and/or fever were included. Those on antidiarrheal treatment were excluded.

Work plan and sample processing: A single fecal sample was obtained from each patient. All stool samples were examined microscopically for fecal Cryptosporidium oocysts by acid-fast staining method prior to and after fecal concentration. Part of each fecal specimen was stored at $-20^{\circ} \mathrm{C}$ in Eppendorf tubes for copro-PCR assays. DNA extraction was done using the Favor Prep stool DNA isolation Mini Kit (Favorgen Biotech Corporation Ping-Tung 908, Taiwan) according to the manufacturer's instructions. Extracted copro-DNA was amplified by nested PCR (nPCR) targeting Cryptosporidium Oocyst Wall Protien (COWP) Gene, using primers BCOWPF (5-ACC GCT TCT CAA CAA CCA TCT TGT CCT C-3) and BCOWPR (5-CGC ACC TGT TCC CAC TCA ATG TAA ACC C-3̀) which amplify 796 bp fragment (Pedraza-Díaz et al, 2001) and nested primers Cry-15 (5-GTA GAT AAT GGA AGA GAT TGT G-3) and Cry-9 (5-GGA CTG AAA TAC AGG CAT TAT CTT G-3) which amplify 553 bp fragment (Spano et al, 1997). The PCR was carried in a volume of $25 \mu 1$. In the primary reaction, sample was heated to $95^{\circ} \mathrm{C}$ for $4 \mathrm{~min}$, followed by 35 cycles of $94^{\circ} \mathrm{C}$ for $1 \mathrm{~min}$ (denaturation), $63^{\circ} \mathrm{C}$ for $1 \mathrm{~min}$ (annealing), $72^{\circ} \mathrm{C}$ for $1 \mathrm{~min}$ (extension) and a final extension at $72^{\circ} \mathrm{C}$ for $10 \mathrm{~min}$. Secondary amplification reagent concentrations were similar to first PCR except that $2 \mu 1$ of primary PCR product were added instead of genomic DNA template and $8.4 \mu \mathrm{l}$ double distilled water. The secondary PCR cycling condition was denaturation at $94^{\circ} \mathrm{C}$ for $50 \mathrm{sec}$, annealing at $54^{\circ} \mathrm{C}$ for $30 \mathrm{sec}$ and extension at $72^{\circ} \mathrm{C}$ for $50 \mathrm{sec}$. PCR generated amplicons of 553bp, subjected to electrophoresis in $1.5 \%$ agarose gels and visualized by a UV transilluminator after staining with ethidium bromide (Spano et al., 1997; Pedraza-Diaz et al, 2001).

Coproscopy was done in Diagnostic and Research Unit of Parasitic Diseases (DRUP) and copro-PCR assays were carried out at the Molecular Medical Parasitology Lab (LMMP), Department of Medical Parasitology, Faculty of Medicine, Cairo University.

\section{Results}

Of 150 samples examined by microscopy using AF staining, Cryptosporidium spp. oocysts were detected in 2 samples (1.3\%), while $148(98.7 \%)$ samples were free from Cryptosporidium spp., suggesting other etiological diarrheic causes. Using nPCR, Cryptosporidium spp. copro-DNA was detected in 9 samples $(6 \%)$ six molecularly positive cases $(66.7 \%)$ were children under 9 years and predominantly females with statistical significance. Microscopy showed sensitivity of $22 \%$ and specificity of $100 \%$ compared to nPCR and Kappa showed fair agreement between both methods. Details are in tables $(1,2 \& 3)$ and figures $(1 \& 2)$.

Table 1: Microscopic examination using AF stain compared to nPCR $(\mathrm{n}=150)$ to detect Cryptosporidium spp.

\begin{tabular}{|c|c|c|c|c|}
\hline \multicolumn{2}{|c|}{ Item } & nPCR positive & nPCR negative & Total \\
\hline \multirow{3}{*}{$\begin{array}{l}\text { Microscopic } \\
\text { examination }\end{array}$} & $+\mathrm{ve}$ & 2 & 0 & 2 \\
\cline { 2 - 5 } & $-\mathrm{ve}$ & 7 & 141 & 148 \\
\cline { 2 - 5 } & Total & 9 & 141 & 150 \\
\hline
\end{tabular}

Table 2: Age and sex of positive Cryptosporidium samples by microscopy of AF stained fecal smears and nPCR.

\begin{tabular}{|l|l|l|l|l|}
\hline Number & Sex & Age & Microscopy & nPCR \\
\hline 1 & Female & 3 years & Negative & positive \\
\hline 2 & Female & 8 years & Positive & positive \\
\hline 3 & Female & 3 years & Positive & positive \\
\hline 4 & Male & 8 months & Negative & positive \\
\hline 5 & Male & 9 years & Negative & positive \\
\hline 6 & Female & 7 years & Negative & positive \\
\hline 7 & Female & 35 years & Negative & positive \\
\hline 8 & Female & 45 years & Negative & positive \\
\hline 9 & Female & 55 years & Negative & positive \\
\hline
\end{tabular}


Table 3: Diagnostic yield and Kappa agreement of microscopy compared to nPCR for detection of Cryptosporidium spp. among group

\begin{tabular}{|c|c|}
\hline Variants & Microscopy \\
\hline Sensitivity & $22 \%$ \\
\hline Specificity & $100 \%$ \\
\hline PPV & $100 \%$ \\
\hline NPV & $95 \%$ \\
\hline Kappa $^{*}$ & 0.349 \\
\hline
\end{tabular}

* Kappa: <0 Poor agreement, 0.01-0.20 Slight agreement, 0.21-0.40 Fair agreement, 0.41-0.60 Moderate agreement, 0.61-0.80 Substantial agreement, 0.81-1.00 almost perfect agreement

\section{Discussion}

Microscopy is the most commonly used method for routine diagnosis of parasites in developing countries; however, it lacks both sensitivity and specificity (Utzinger et al, 2010). In developing countries, replacing microscopy with more sensitive and specific molecular methods is usually hindered by the cost (Taniuchi et al, 2011).

In the present study, the low Cryptosporidium oocysts copro-prevalence $(1.3 \%)$ found by microscopy using AF stain agreed with El- Helaly et al. (2012) who detected Cryptosporidium oocysts in $2.6 \%$ of diarrheic stools of patients attending the Stanley Medical College Hospital, Alexandria by using microscopy with AF stain. In Greater Cairo, Nazeer et al. (2013) reported Cryptosporidium oocysts in $1 \%$ of cases and Banisch et al. (2015) reported 7 cases of cryptosporidiosis (6.7\%) using immunochromatographic assay (ICA) not detected by microscopy. Perch et al. (2001) in West Africa reported (7.7\%) in diarrheic patients. Stark et al. (2011) in Australia detected Cryptosporidium oocysts in $1.1 \%$ of samples submitted to St. Vincent's Hospital, Sydney and Acquah et al. (2012) in Ghana reported (7.3\%) oocysts of Cryptosporidium. However, higher prevalence of cryptosporidiosis was reported by Al Braiken et al. (2003) in Saudi Arabia, using microscopy detected Cryptosporidium oocysts in stools of $32 \%$ of children with diarrhea with AF stain. El-Hamshary et al. (2008) and El-Settawy and Fathy (2012) in Egypt reported $21 \%$ and $18.6 \%$ respectively using microscopy with AF stain.

In the present study, due to incompliance of the patients and inability to examine three successive specimens, the reported microscopic prevalence of Cryptosporidium spp. might be considered lower than expected.
In general, decreased sensitivity of $\mathrm{AF}$ stain for detection of Cryptosporidium spp. was explained by the high threshold necessary (a concentration of 10,000 oocysts/g of watery stool) for oocyst detection in stool specimens (Weber et al, 1991). Also, there might be some variability in stain uptake, related to the stain itself or the age of the oocyst after prolonged storage (Current and Garcia, 1991).

In the present study, more cases were detected using nPCR targeting Cryptosporidium COWP gene of Cryptosporidium coproDNA. Many studies reported using nPCR for detection of Cryptosporidium spp and stated that PCR proved more sensitive compared to microscopy with conventional staining (Kaushik et al, 2008; Stark et al, 2011; Fathy et al, 2014; El-Badry et al, 2015; Abdelrazek et al, 2016; Ghallab et al, 2016). In the present study, there was a significant predominance of Cryptosporidium copro-DNA detection in children as compared with adults. While Cryptosporidium affected both sexes, there was a significant predominance in females. Predominance of cryptosporidiosis in children and contradictory sex predominance was reported in many studies from different countries (ANOFEL, 2010; Abd El-Kader et al, 2012; El-Badry et $a l, 2015)$. Predominance of cryptosporidiosis in children may be due to the absence of pre-existing immunity as well as more exposure to recreational water, increasing the risk of getting infected. Also, previous studies have reported a more frequent attendance of diarrheic children than adults in outpatient clinics (ANOFEL, 2010; Abd El-Kader et al, 2012; El-Badry et al, 2015).

The low prevalence of Cryptosporidium detection (6\%) agreed with Abd El-Kader et al. (2012) who reported cryptosporidiosis in 
children patients suffering from diarrhea (4.6\%) using nPCR, and Banisch et al. (2015) who reported 7 cases $(6.7 \%)$ using ICA majority were adults. On the other hand, higher prevalence rates ranged from $16-25 \%$ were recorded in stool of diarrheic Egyptian children agreed with studies carried out in Cairo using nPCR (Fathy et al, 2014; El-Badry et al, 2015; Abdelrazek et al, 2016; Ghallab et al, 2016), and in adult patients in Ismalia Governorate (El-Hamshary et al, 2008) and Zagazig (El-Settawy and Fathy 2012).

PCR-based methods proved higher sensitivity and must replace the conventional methods for detection of many protozoa, including Cryptosporidium (Tumwine et al, 2003; El-Hamshary et al, 2008; Fathy et al, 2014; El-Badry et al, 2015; Ghallab et al, 2016), because of high sensitivity, specificity, easy performance of copro-PCR amplification technique and as an obvious choice for improved detection of Cryptosporidium in stool samples.

\section{Conclusion}

There was a relatively low prevalence of Cryptosporidium, with a predominance of child and female cases. The conventional microscopic and staining techniques used for the diagnosis of Cryptosporidium spp. are limited by its low sensitivity, while PCR assays are more sensitive and specific. There is under-diagnosis of Cryptosporidium as most labs rely on stained fecal smears for detection and physicians do not request stool analysis for Cryptosporidium.

\section{References}

Abd El Kader, NM, Blanco, MA, Ali-Tammam, M, Abd El Ghaffar, R, Osman, A, et al, 2012: Detection of Cryptosporidium parvum and Cryptosporidium hominis in human patients in Cairo, Egypt. Parasitol. Res. 110:161-6.

Abdel-Messih, IA, Wierzba, TF, Abu-Elyazeed, R, Ibrahim, AF, Ahmed, SF, et al, 2005: Diarrhea associated with Cryptosporidium parvum among young children of the Nile River Delta in Egypt. J. Trop. Pediatr. 51:154-59.

Abdelrazek NM, Al-Antably ASA, Fathy M
M, El-Badry AA, 2016: Copro-molecular charact-erization of Cryptosporidium spp. and genotypes among Egyptian children. J. Egypt. Soc. Parasitol. 46, 2:385-96.

Acquah, F, Tay, SCK, Frimpong, EH, 2012: Prevalence of Cryptosporidium and Isospora belli in HIV/AIDS patients at Komfo Anokye Teaching Hospital, Kumasi-Ghana. Int. J. Pure Appl. Sci. Technol. 8:26-33.

AL-Braiken, FA, Amin, A, Beeching, NG, Hommel, M, Hart, CA, 2003: Detection of Cryptosporidium amongst diarrheic and asymptomatic children in Jeddah, Saudi Arabia. Ann. Trop. Med. Parasitol. 97:1-5.

ANOFEL, 2010: Cryptosporidium National Network Laboratory: Based surveillance for Cryptosporidium in France, 2006-2009. Euro Surveill 15, 33:19642.

Banisch, DM, El-Badry, AA, Klinnert, JV, Ignatius, R, El-Dib, N, 2015: Simultaneous detection of Entamoeba histolytica/dispar, Giardia duodenalis and Cryptosporidia by immunochromatographic assay in stool samples from patients living in the Greater Cairo region, Egypt. World J. Microbiol. Biotechnol. 31, 8:1251-8.

Calderaro, A, Gorrini, C, Montecchini, S, Peruzzi, S, Piccolo, G, et al, 2010: Evaluation of a real-time polymerase chain reaction assay for the laboratory diagnosis of giardiasis. Diag. Microbiol. Infect. Dis. 66:261-7.

Current, WL, Garcia, LS, 1991: Cryptosporidiosis. Clin. Microbiol. Rev. 4:325-8.

El-Badry AA, Al-Antably ASA, Hassan MA, Hanafy NA, Abu-Sarea EY, 2015: Molecular seasonal, age and gender distributions of Cryptosporidium in diarrhoeic Egyptians: Distinct endemicity. Eur. J. Clin. Microbiol. Infect. Dis. 34, 12:2447-53.

El-Hamshary, EM, El-Sayed, HF, Hussein, E M, Rayan, HZ, Rasha, H et al, 2008: Comparison of polymerase chain reaction, immunochromatographic assay and staining techniques in diagnosis of cryptosporidiosis. PUJ1, 1:77-86. El-Helaly, NS, Aly, MA, Attia, SS, 2012: Detection of Cryptosporidium Infection among Children with Diarrhea. New York Sci. J. 5:68-76.

El-Settawy, MA, Fathy, GM, 2012: Evaluation and comparison of PCR, coproantigen ELISA and microscopy for diagnosis of Cryptosporidium in human diarrhoeic specimens. J. Am. Sci. 8:1385-78.

El Shazly, AM, Soltan, DM, El-Sheikha, HM, 
Sadek, GS, Morsy, AT, 2007: Correlation of ELISA copro-antigen and oocysts count to the severity of cryptosporidiosis parvum in children. J. Egypt. Soc. Parasitol. 37, 1:107-20.

Fathy, MM, Abdelrazek, NM, Hassan, FA, El-Badry, AA, 2014: Molecular copro-prevalence of Cryptosporidium in Egyptian children and evaluation of three diagnostic methods. Indian Pediatr. 5, 9:727-9.

Fayer, R, Morgan, U, Upton, SJ, 2000: Epidemiology of Cryptosporidium: transmission, detection and identification. Int. J. Parasitol. 30: 1305-22.

Ghallab, MMI, Abdel-Aziz, I.Z, Shoeib, EY, El-Badry, AA, 2016: Laboratory utility of coproscopy, copro immunoassays and copro nPCR assay targeting Hsp90 gene for detection of Cryptosporidium in children, Cairo, Egypt. J. Parasit. Dis. 40, 3:901-5.

Ghosh, S, Debnath, A, Sil, A, De, S, Chattopadhyay, DJ, et al, 2000: PCR detection of Giardia lamblia in stool: targeting intergenic spacer region of multicopy rRNA gene. Mol. Cell. Probes 14:181-9.

Hadfield, SJ, Robinson, G, Elwin, K, Chalmers, RM, 2011: Detection and differentiation of Cryptosporidium spp. in human clinical samples by use of real-time PCR. J. Clin. Microbiol. 49: 918-24.

Hamzah, Z, Petmitr, S, Mungthin, M, Leelayoova, S, Chavalitshewinkoon, P. 2010: Development of multiplex real-time polymerase chain reaction for detection of Entamoeba histolytica, Entamoeba dispar, and Entamoeba moshkovskii in clinical specimens. Am. J. Trop. Med. Hyg. 83:909-13.

Haque, R, Roy, S, Siddique, A, Mondal, U, Mazidur-Rahman, SM, et al, 2007: Multiplex Real-Time PCR assay for detection of Entamoeba histolytica, Giardia intestinalis and cryptosporidium spp. Am. J. Trop. Med. Hyg. 76:713-7.

Kaushik, K, Khurana, S, Wanchu, A, Malla, N, 2008: Evaluation of staining techniques, antigen detection and nested PCR for the diagnosis of cryptosporidiosis in HIV seropositive and seronegative patients. Acta Trop. 107:1-7.

Mousa, KM, Abdel-Tawab, AH, Khalil, HH, El-Hussieny, NA, 2010: Diarrhea due to parasites particularly Cryptosporidium parvum in great Cairo, Egypt. J. Egypt. Soc. Parasitol. 40: 439-50.

Nazeer, JT, Khalifa, KE, Thien, HV, El-Siba- ei, MM, Abdel-Hamid, MY, et al, 2013: Use of multiplex real-time PCR for detection of common diarrhea causing protozoan parasites in Egypt. Parasitol. Res.112:595-601.

Pedraza-Díaz, S, Amar, C, Nichols, GL, McLauchlin, J, 2001: Nested polymerase chain reaction for amplification of the Cryptosporidium oocyst wall protein gene. Emerg. Infect. Dis. 7: 49-56.

Perch, M, Sodeman, M, Jakobsen, MS, Valentiner-Branth, P, Steinsland, H, et al, 2001: Seven years' experience with Cryptosporidium parvum in Guinea-Bissau, West Africa. Ann. Trop. Paediatr. 21:313-8.

Spano, F, Putignani, L, McLauchlin, J, Casemore, D, Crisanti, A, 1997: PCR-RFLP analysis of the Cryptosporidium oocyst wall protein (cowp) gene discriminates between $C$. wrairi and $C$. parvum, and between $C$. parvum isolates of human and animal origin. FEMS Microbiol. Lett, 150:209-17.

Stark, D, Al-Qassab, SE, Barratt, JL, Stanley, K, Roberts, T, et al, 2011: Evaluation of multiplex tandem real-time PCR for detection of Cryptosporidium spp., Dientamoeba fragilis, Entamoeba histolytica, and Giardia intestinalis in clinical stool samples. J. Clin. Microbiol. 1: 257-62.

Stark, D, van Hal, S, Fotedar, R, Butcher, A, Marriott, D, et al, 2008: Comparison of stool antigen detection kits to PCR for diagnosis of amebiasis. J. Clin. Microbiol. 46:1678-81

Taniuchi, M, Verweij, JJ, Noor, Z, Sobuz, S U, Lieshout, LV, et al, 2011: High throughput multiplex PCR and probe-based detection with Luminex beads for seven intestinal parasites. Am. J. Trop. Med. Hyg. 84:332-7.

Tumwine, JK, Kekitinwa, A, Nabukeera, N, Akiyoshi, DE, Rich, SM. et al, 2003: Cryptosporidium parvum in children with diarrhea in $\mathrm{Mu}-$ lago Hospital, Kampala, Uganda. Am. J. Trop. Med. Hyg. 68:710-5.

Utzinger, J, Botero-Kleiven, S, Castelli, F, Chiodini, PL, Edwards, H, et al, 2010: Microscopic diagnosis of sodium acetic acid-formalinfixed stool samples for helminthes and intestinal protozoa: a comparison among European reference laboratories. Clin. Microbiol. Infect. 16: 267-73.

Weber, R, Bryan, R, Juranek, D, 1991: Improved stool concentration procedures for detection of Cryptosporidium oocysts in in fecal specime- 
ns. J. Clin. Microbiol. 30:2869-73.

WHO, 2012: The World Health Report: Make Every Mother and Child Count. Geneva.

WGO, 2013: (World Gastroenterology Organization Global Guidelines): Acute Diarrhea in
Adults and Children: A Global Perspective.

Youssef, FG, Adib, I, Riddle, MS, Schlett, CD

A, 2008: Review of Cryptosporidiosis in Egypt.

J. Egypt. Soc. Parasitol. 38:9-28.

\section{Explanation of figures}

Fig.1: Cryptosporidium spp. oocysts stained with AF stain and viewed by oil immersion lens (x1000).

Fig.2: Agarose gel electrophoresis for products of nPCR targeting COWP gene of Cryptosporidium spp. at $553 \mathrm{bp}$. Lane 1, 2, 3, 5: negative cases, Lane 4, 6, 7, 8: positive cases, Lane 9: positive control, Lane 10: negative control.
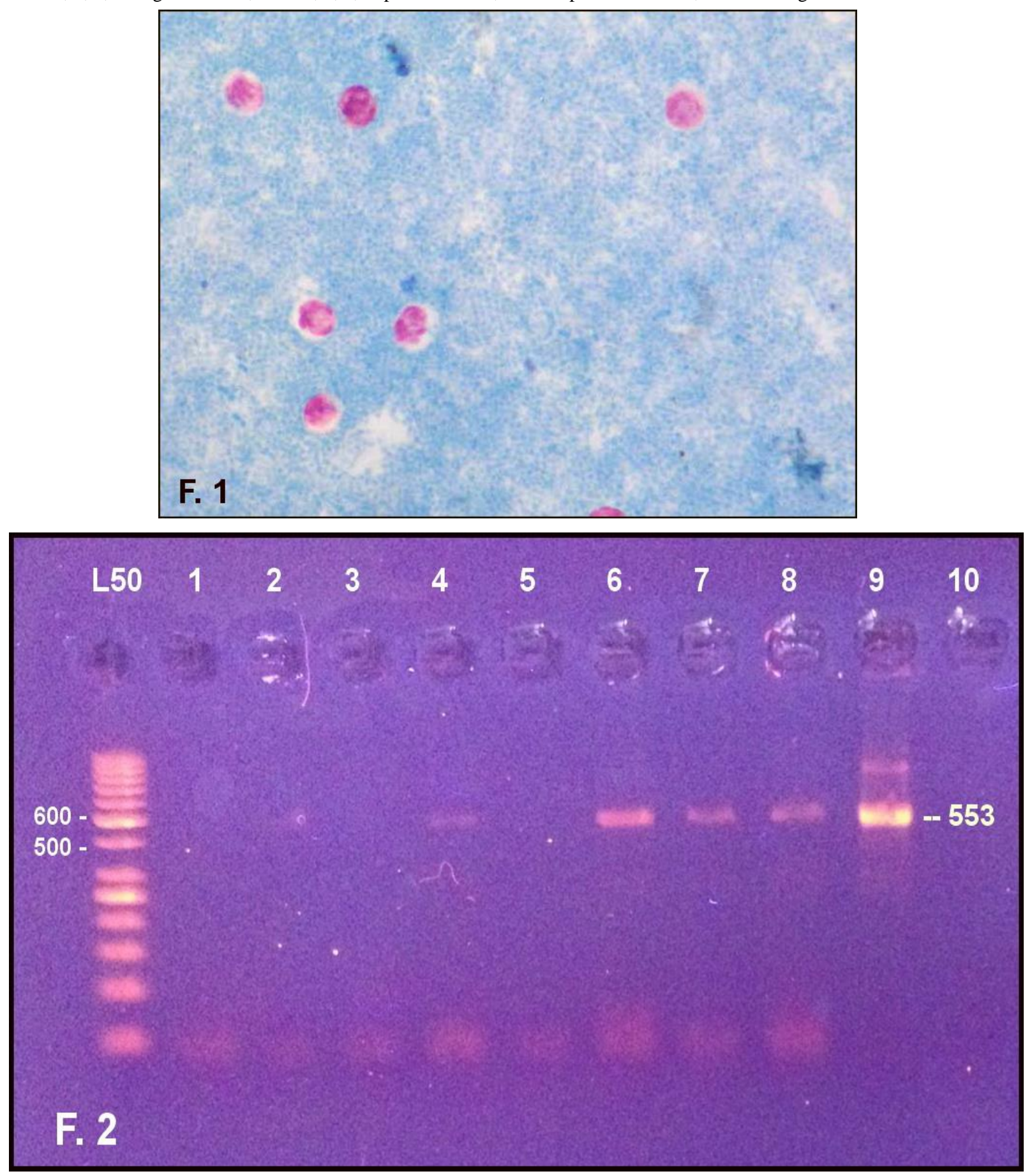